\title{
THE ROLE OF DIFFERENT HIGH ENERGY BALL MILLING CONDITIONS OF MOLYBDENUM POWDER ON THE RESULTING PARTICLES SIZE AND MORPHOLOGY
}

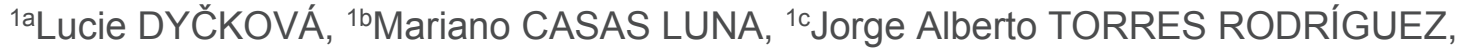

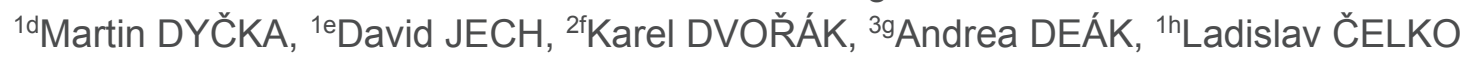 \\ ${ }^{1}$ Brno University of Technology, Central European Institute of Technology, Brno, Czech Republic, EU \\ alucie.dyckova@ceitec.vutbr.cz, ${ }^{b}$ mariano.casasluna@ceitec.vutbr.cz, \\ cjorgealberto.torresrodriguez@ceitec.vutbr.cz, dmartin.dycka@ceitec.vutbr.cz, edavid.jech@ceitec.vutbr.cz, \\ hladislav.celko@ceitec.vutbr.cz \\ ${ }^{2}$ Brno University of Technology, Faculty of Civil Engineering, Brno, Czech Republic, EU \\ fdvorak.k.@ceitec.vutbr.cz,
}

${ }^{3}$ Hungarian Academy of Sciences, Research Centre for Natural Sciences, TTK AKI, Budapest, Hungary, EU gdeak.andrea@ttk.mta.hu,

https://doi.org/10.37904/metal.2019.927

\begin{abstract}
High energy ball milling is a powder processing method in which the powder particle size can be decreased to micrometer size in a relatively short period of time. This method is based on the friction and the high energy kinetic collisions between the balls and the trapped powder particles. The milling process is influenced by many process variables such as mainly the rotational speed, ball to powder weight ratio and processing time. In the present study, high energy ball milling process was performed for molybdenum powder using a high energy ball mill under different milling conditions varying the: (i) rotational speed from 600 to $800 \mathrm{rpm}$, (ii) ball to powder weight ratio of 100:3 and 100:6, (iii) milling time in the range of 10 to 60 minutes, (iv) process control agent using polyethylene glycol, and $(\mathrm{v})$ milling atmosphere under air or nitrogen. The used initial molybdenum powder was of globular morphology and $100 \mu \mathrm{m}$ in particle size. The powders after milling were characterized by a scanning electron microscope (SEM) and a laser diffraction size analysis. The particle size of milled powders was decreased down to $1.1 \mu \mathrm{m}$. As the most effective ball to powder weight ratio was found 100:6 with the milling speed of $800 \mathrm{rpm}$. The milling time played a crucial role for the refinement of particles up to $45 \mathrm{~min}$, where the further milling had negligible effect on the overall trend of particle size evolution.
\end{abstract}

Keywords: High energy ball milling, milling parameters, molybdenum, particle size, granulometry

\section{INTRODUCTION}

The refractory metals and their alloys are important and attractive group of materials, which are used in high temperature applications such as aerospace, nuclear and military industries, because of their high melting temperature ranging from $2468{ }^{\circ} \mathrm{C}(\mathrm{Nb})$ to $3410{ }^{\circ} \mathrm{C}(\mathrm{W})$ [1]. Due to it, they are generally produced by the means of powder metallurgy. Among of all refractory metals, the molybdenum is an important one due to its considerable physical properties such as good elevated-temperature strength, mechanical stability, good thermal conductivity $\left(138 \mathrm{~W} \cdot \mathrm{m}^{-1} \cdot \mathrm{C}^{-1}\right)$ and low specific heat $\left(25.1-28.4 \mathrm{~J} \cdot \mathrm{K}^{-1} \cdot \mathrm{mol}^{-1}\right.$ at $\left.400-1000 \mathrm{~K}\right)$ [2]. The production of molybdenum parts is demanding because of its high melting temperature and ductile-to-brittle transition temperature $\left(27^{\circ} \mathrm{C}\right)$. With the respect to this, the powder metallurgy is often selected for molybdenum production because it is the easier way how to obtain Mo parts with minimal cost.

The high energy ball milling (HEBM) is an effective solid-state method for production of powders with attractive properties such as ductile flakes $(\mathrm{Ag}, \mathrm{Ti}, \mathrm{Zn})$, nanocrystalline materials $\left(\mathrm{Mg}_{2} \mathrm{Ni}\right)$, or well dispersed phased materials. HEBM can result in the: (i) particle size reduction, (ii) mechanical alloying, and (iii) reactive milling. During the high energy ball milling the friction and the high energy kinetic collisions are the main processes, 
under which the powder particles are repeatedly subjected to deformation, cold-welding and fracturing. Especially at the beginning of milling, the friction and the fracturing are dominant processes that result in the particle size reduction. With further milling, the powder particle size starts to grow through dominant coldwelding process until steady-state equilibrium. If it is necessary to reduce powder particle size and if the milling parameters are set correctly, then the milling time plays key role and determines when the cold-welding process starts to be dominant and when the longer milling has negligible effect on the overall trend of particle size evolution.

Thus, the main objective of this study was to investigate and determine the role of different high energy ball milling conditions of molybdenum powder on the resulting particle size and morphology. The milling variables were the: (i) rotational speed, (ii) ball to powder weight ratio, (iii) milling time, (iv) process control agent, and (v) milling atmosphere.

\section{EXPERIMENTAL MATERIAL AND METHODS}

\subsection{Experimental material}

Molybdenum powder (30.63.2, GTV GmbH, Germany) was supplied in agglomerated and sintered state with chemical composition about $99.0 \mathrm{wt} \%$ molybdenum, $0.1 \mathrm{wt} \%$ oxygen and $0.9 \mathrm{wt} \%$ impurities. The powder particles were irregular spheres of $100 \mu \mathrm{m}$ in size. The overview and the detail of initial powder are shown in Figure 1.
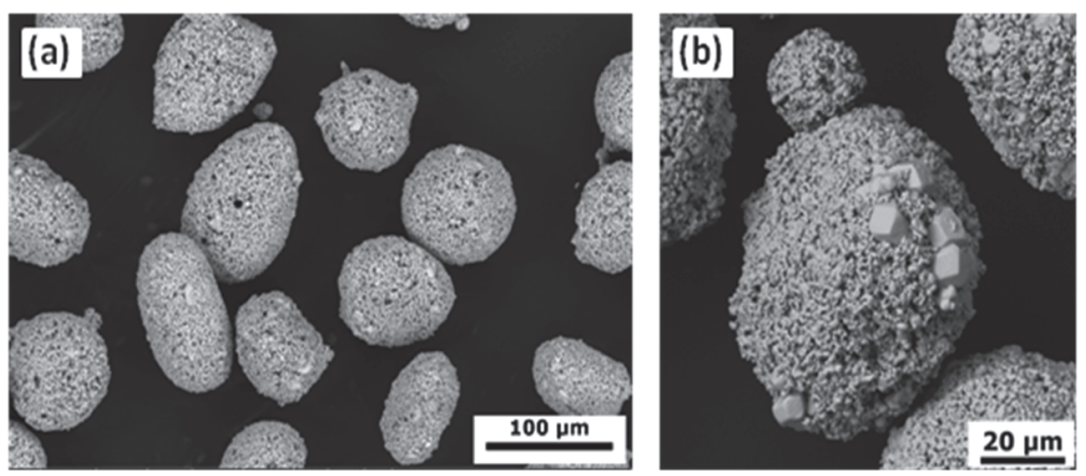

Figure 1 SEM micrographs of initial powder: (a) the overview, and (b) the detail of a single particle.

\subsection{Experimental procedure and methods}

The experiments were carried out using the high energy ball mill Simoloyer CM-01 (Zoz GmbH, Germany). The steel balls of $5 \mathrm{~mm}$ were used as a grinding media. The weight of initial powders was $30 \mathrm{~g}$ and $60 \mathrm{~g}$. To study the influence of polyethylene glycol (PEG) and milling atmosphere, the PEG of $0.5 \mathrm{~mL}$ was added into the mill chamber. Before the milling in nitrogen atmosphere, the mill container was at least twice evacuated and subsequently filled with nitrogen gas. The analyses and evaluation of milled powders were carried out via scanning electron microscopy (Lyra3, Tescan, Czech Republic). The granulometry of powder was measured by the laser diffraction size analysis using Mastersizer 2000 (Malvern Instruments Ltd., England).

\section{RESULTS}

\subsection{The influence of distinct ball to powder weight ratio on particle size}

The influence of distinct ball to powder weight ratio (BPR) was investigated with constant rotational speed (600 rpm) and milling time (10 min) with the use of PEG and air atmosphere. The BPR was set to: (i) 100:3 and (ii) 100:6. The typical powder morphologies for each batch are shown in Figure 2. At both BPRs, the 
sintered and agglomerated powder particles were partially broken. In the case of BPR (100:3), the particles were finer and more fractured. Thus, the efficiency of milling was in this case higher due to greater energy of collisions. This higher efficiency is also obvious from the laser diffraction size analysis (Table 1), where the milled powder with BPR (100:3) was in size of $D(0.1) 3.0 \mu \mathrm{m}, \mathrm{D}(0.5) 18.3 \mu \mathrm{m}$ and $\mathrm{D}(0.9) 72.3 \mu \mathrm{m}$, and the milled powder with BPR (100:6) was in size of $D(0.1) 5.2 \mu \mathrm{m}$, $D(0.5) 45.5 \mu \mathrm{m}$ and $D(0.9) 101.5 \mu \mathrm{m}$. Since the particle size reduction was main goal of this study, for the next experiments the BPR of 100:6 was chosen to avoid further plastic deformation and to obtain more favorable conditions for the additional variation of the other milling parameters.
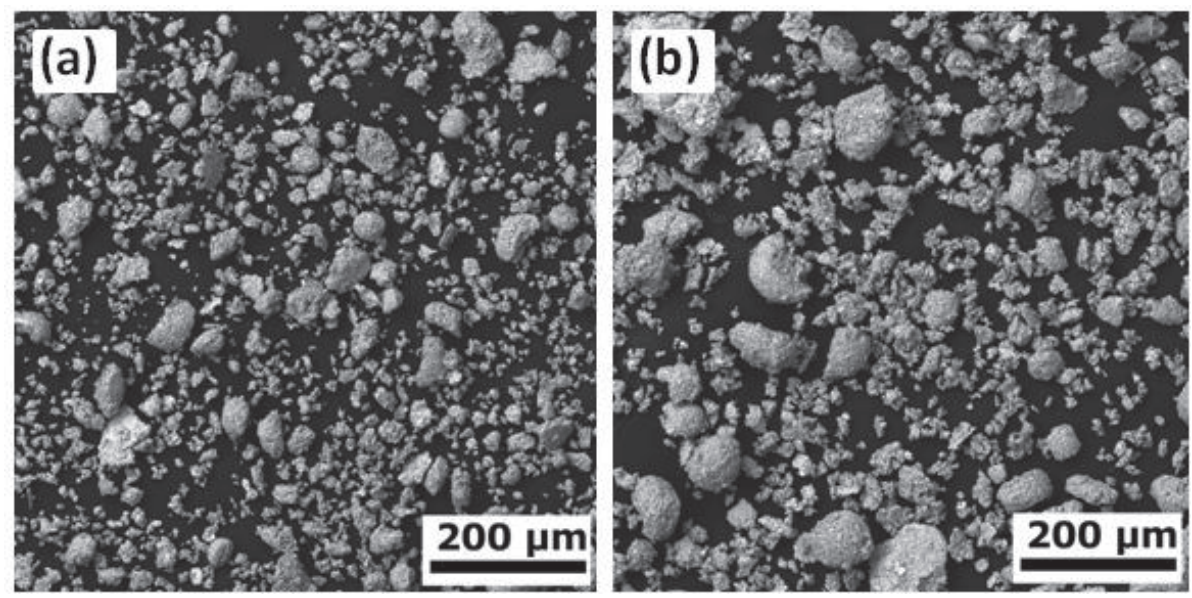

Figure 2 High energy milled powders at $600 \mathrm{rpm}, t=10$ min with: (a) BPR 100:3, (b) 100:6.

Table 1 Determination of particle size by the laser diffraction size analysis for different BPR

\begin{tabular}{|c|c|c|c|}
\hline Milling conditions & $\boldsymbol{D}(\mathbf{0 . 1})(\mu \mathrm{m})$ & $\boldsymbol{D}(\mathbf{0 . 5})(\mu \mathrm{m})$ & $\boldsymbol{D}(\mathbf{0 . 9})(\boldsymbol{\mu m})$ \\
\hline $100: 3$ & 3.0 & 18.3 & 72.3 \\
\hline $100: 6$ & 5.2 & 45.5 & 101.5 \\
\hline
\end{tabular}

\subsection{The influence of milling atmosphere and process control agent on particle size}

The influence of milling atmosphere was investigated under air and nitrogen atmosphere, where the milling speed was set at $600 \mathrm{rpm}$, the BPR at 100:6 with constant milling time (10 min). The typical morphology of milled powders is shown in Figure 3, where the used atmosphere was air (Figure 3a and $\mathbf{3 b}$ ) or nitrogen (Figure $\mathbf{3 c}$ and $\mathbf{3 d}$ ). The influence of process control agent was investigated with the PEG (Figure $3 \mathbf{a}$ and $3 \mathbf{c}$ ). As can be seen, the PEG had a negative influence on particle size reduction. According to the laser diffraction size analysis (Table 2), there is no difference in the particle size with the use of different atmospheres, and with the combinations of distant atmospheres and PEG. Therefore, the finest particle size was achieved by milling in atmosphere (air or nitrogen) without PEG, where the milled powder particles in air atmosphere had mean size $D(0.5)$ of $19.4 \mu \mathrm{m}$, and in nitrogen atmosphere had mean size $D(0.5)$ of $20.3 \mu \mathrm{m}$. As can be seen in Figure 4, there were the cold-welded particles in size of 200-400 $\mu \mathrm{m}$ for milling in air or nitrogen atmosphere without PEG. On the contrary after the milling with PEG, the mean particle size D (0.5) was $45.5 \mu \mathrm{m}$ in air, and 38.1 $\mu \mathrm{m}$ in nitrogen. In these both cases with PEG, the average cold-welded particles' size was of 300-700 $\mu \mathrm{m}$. Furthermore, compared to the milling in air or nitrogen atmosphere without PEG, the volume of cold-welded particles was increased about of $35 \mathrm{vol} \%$; so it can be assumed, that the use of PEG had a negative effect on the particle size reduction. The nitrogen atmosphere could have a beneficial effect, when a reactive powder is milled. From another experiments, it was confirmed that used initial molybdenum powder did not react with air during the milling. 

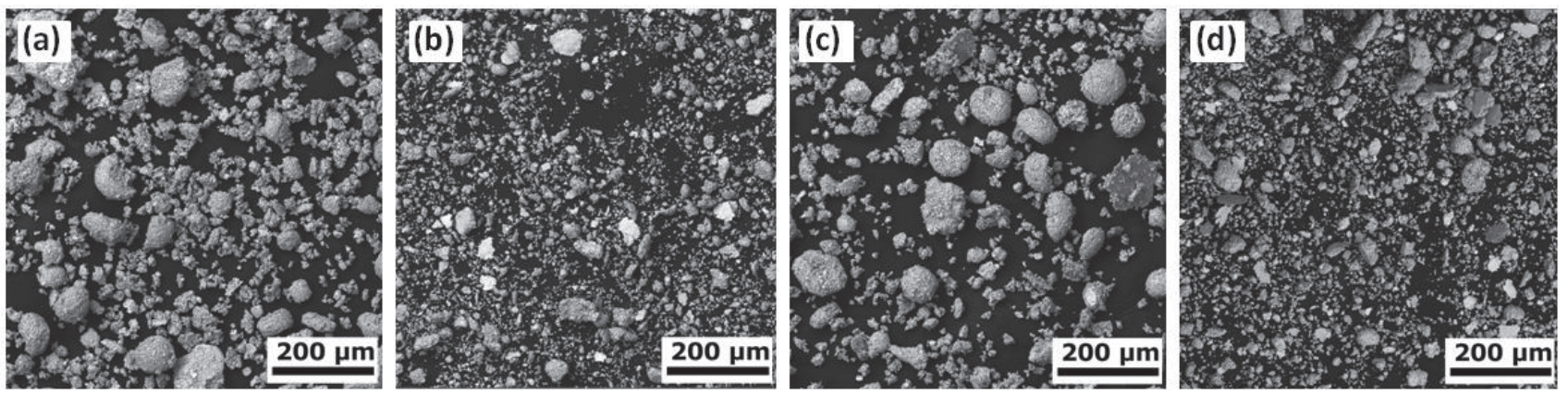

Figure 3 High energy milled powder at 600 rpm, BPR = 100:6 using: (a) air atmosphere with PEG, (b) air atmosphere, (c) nitrogen atmosphere with PEG, (d) nitrogen atmosphere

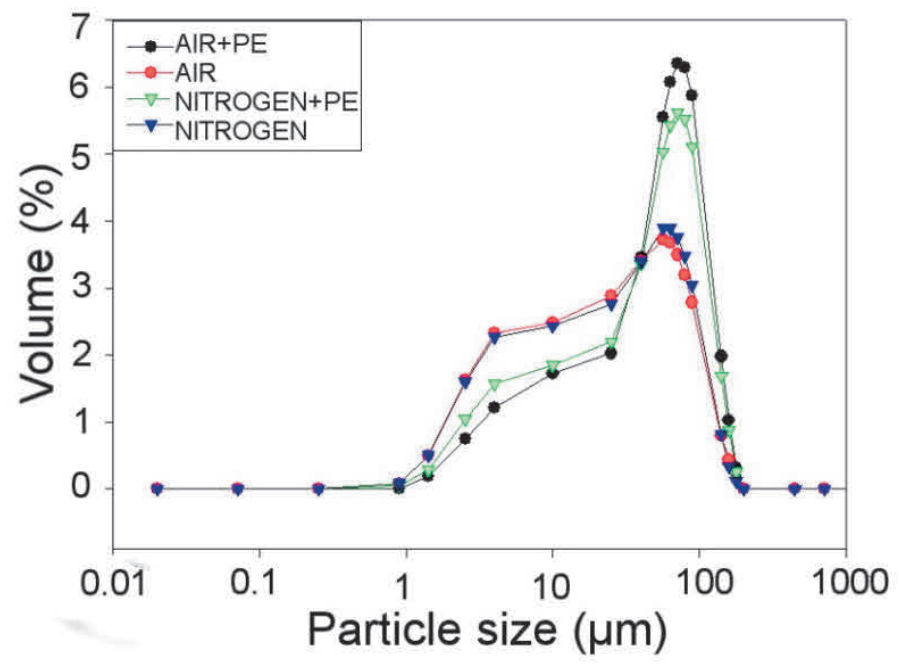

Figure 4 Effect of different milling atmosphere and PEG on the particle size of initial molybdenum powder at $600 \mathrm{rpm}, \mathrm{BPR}=100: 6, \mathrm{t}=10 \mathrm{~min}$

Table 2 Determination of particle size by the laser diffraction size analysis for the examination of PCA role

\begin{tabular}{|c|c|c|c|}
\hline Milling conditions & $\boldsymbol{D}(\mathbf{0 . 1})(\mu \mathrm{m})$ & $\boldsymbol{D}(\mathbf{0 . 5})(\boldsymbol{\mu m})$ & $\boldsymbol{D}(\mathbf{0 . 9})(\boldsymbol{\mu m})$ \\
\hline Air + PE & 5.2 & 45.5 & 101.5 \\
\hline Air & 3.0 & 19.4 & 78.0 \\
\hline $\mathrm{N}_{2}+\mathrm{PE}$ & 4.0 & 38.1 & 97.5 \\
\hline $\mathrm{N}_{2}$ & 3.0 & 20.3 & 79.3 \\
\hline
\end{tabular}

\subsection{The influence of various rotational speed on particle size}

The determination of optimal rotational speed was done with BPR of 100:6, constant milling time (10 min) in air atmosphere. The rotational speed was set to: (i) $600 \mathrm{rpm}$, (ii) $700 \mathrm{rpm}$, and (iii) $800 \mathrm{rpm}$. The representative SEM micrographs of milled powders for each rotational speed are shown in Figure $\mathbf{5}$ and the results of the laser diffraction size analysis are listed in Table 3. As can be seen, the powder particles became finer and more fractured with increasing rotational speed. This is also in agreement with the results of the granulometry, where the finest particles are in size of $D(0.1) 2.5 \mu \mathrm{m}, \mathrm{D}(0.5) 13.2 \mu \mathrm{m}$ and $\mathrm{D}(0.9) 72.6 \mu \mathrm{m}$ for the milled powder at $800 \mathrm{rpm}$. The particle size evolution (Figure 6) shows the broad peak for milled powder at $800 \mathrm{rpm}$ which indicates better particle size distribution through whole range compared to the curves of milled powder at $600 \mathrm{rpm}$ and $700 \mathrm{rpm}$. At this rotational speed, all initial powder particles were fractured additionally in more than 60 vol\% (Figure 6) compared to the lower rotational speeds. 

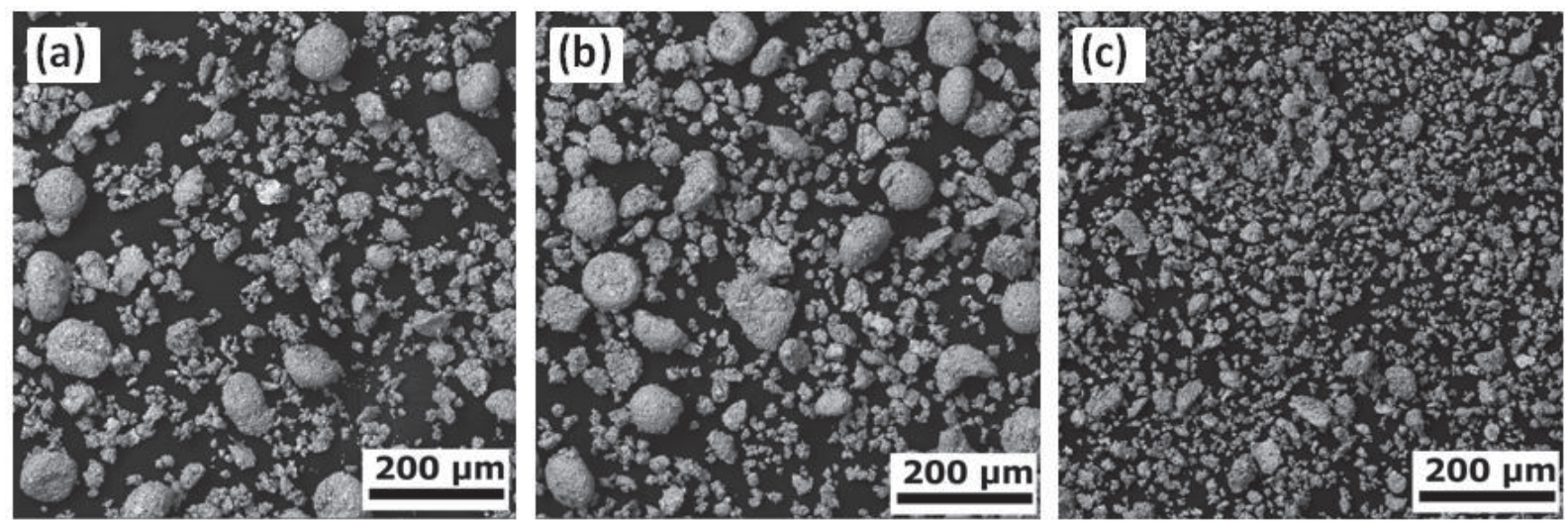

Figure 5 SEM micrographs of high energy milled powders with $B P R=100: 6, t=10 \mathrm{~min}$ at: (a) $600 \mathrm{rpm}$, (b) $700 \mathrm{rpm}$, (c) $800 \mathrm{rpm}$.

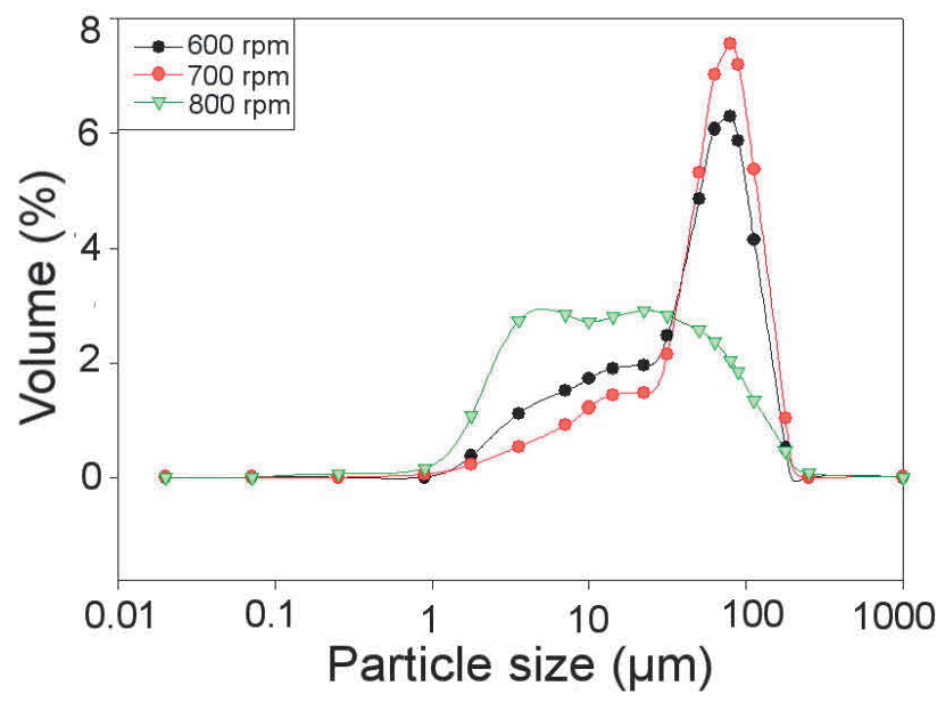

Figure 6 Effect of different milling speed with BPR $=100: 6, t=10 \mathrm{~min}$.

Table 3 Determination of particle size by the laser diffraction size analysis for the examination of rotational speed

\begin{tabular}{|c|c|c|c|}
\hline Rotation speed $(\mathrm{rpm})$ & $\boldsymbol{D}(\mathbf{0 . 1})(\boldsymbol{\mu m})$ & $\boldsymbol{D}(\mathbf{0 . 5})(\boldsymbol{\mu m})$ & $\boldsymbol{D}(\mathbf{0 . 9})(\boldsymbol{\mu m})$ \\
\hline 600 & 5.2 & 45.5 & 101.5 \\
\hline 700 & 9.2 & 57.9 & 113.8 \\
\hline 800 & 2.5 & 13.2 & 72.6 \\
\hline
\end{tabular}

\subsection{The influence of milling time on particle size}

To determinate the most suitable milling time for the particle size reduction, the rotational speed was set at 800 rpm with BPR = 100:6 in air atmosphere. The milling time was set to: (i) $20 \mathrm{~min}$, (ii) $30 \mathrm{~min}$, (iii) $45 \mathrm{~min}$, and (iv) 60 min. The typical morphology of each batch is shown in Figure 7. As can be seen, the particle size became finer with longer duration of milling until $45 \mathrm{~min}$. Up to this milling time; the powder particles mainly tend to fracture (see Figure 8). And after this point (milling for $60 \mathrm{~min}$ ), the powder particles started to grow and cold-weld in higher volume ( $10 \mathrm{vol} \%)$. The volume of finer powder particles decreased of $15 \mathrm{vol} \%$ in comparison to the volume of finer particles of milled powder at $45 \mathrm{~min}$. It can be assumed, that the milling system would reach the steady-state with longer milling at this rotational speed $(800 \mathrm{rpm})$. The results of 
particle size from the laser diffraction size analysis are listed in Table 4. The powder particles milled for 20 min were in size of $D(0.1) 3.0 \mu \mathrm{m}, \mathrm{D}(0.5) 16.7 \mu \mathrm{m}$ and $\mathrm{D}(0.9) 117.6 \mu \mathrm{m}$, whereas the powder particles milled for $45 \mathrm{~min}$ reached size of $\mathrm{D}(0.1) 1.7 \mu \mathrm{m}, \mathrm{D}(0.5) 4.6 \mu \mathrm{m}$ and $\mathrm{D}(0.9) 89.1 \mu \mathrm{m}$. Thus, the finest particle size $(D(0.1))$ was almost twice smaller, and the mean particle size (D (0.5)) was more than three times smaller in case of milling for $45 \mathrm{~min}$. The particle size evolution of powder milled for 45 min shows main difference between shorter and longer times. From this point of milling, the particle size distribution was divided into two main fractions, which had their peaks in $2 \mu \mathrm{m}$ and $120 \mu \mathrm{m}$. At these milling conditions, it was achieved the finest particles in size of $1.1 \mu \mathrm{m}$ and the biggest particles in size of $400 \mu \mathrm{m}$.
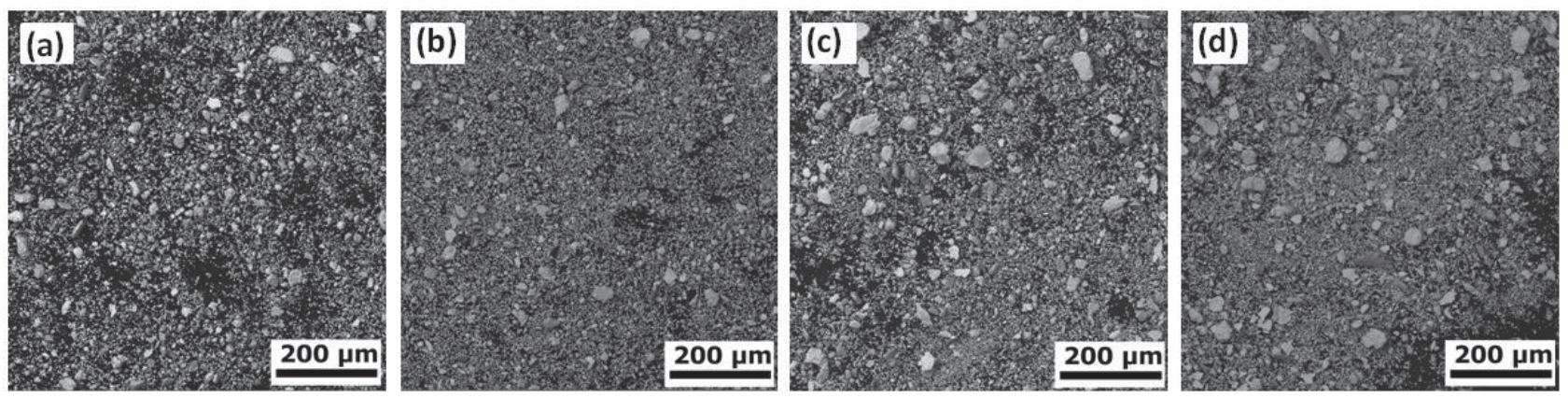

Figure 7 High energy milled powder at 800 rpm, BPR = 100:6 with milling time of: (a) 20 min, (b) 30 min, (c) $45 \mathrm{~min},(\mathrm{~d}) 60 \mathrm{~min}$.

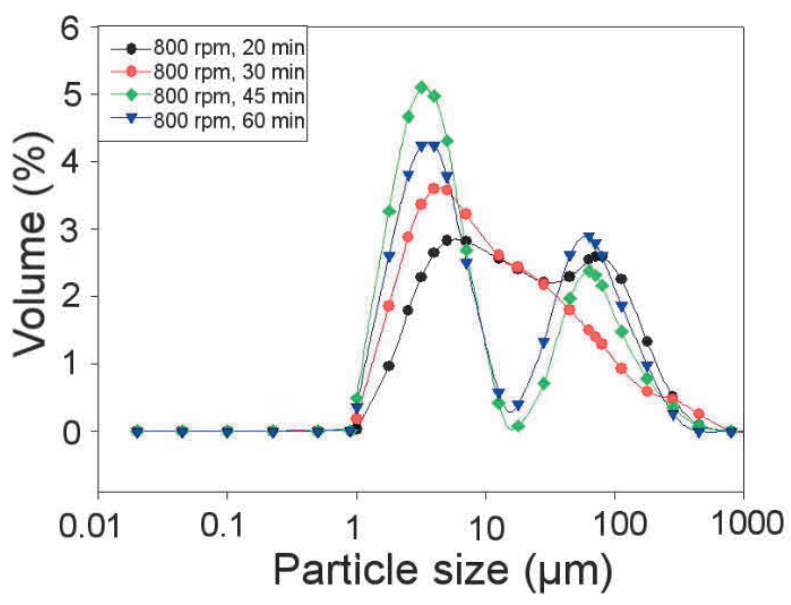

Figure 8 Effect of different milling time on particle size of initial molybdenum powder at 800 rpm.

Table 4 Determination of particle size by the laser diffraction size analysis for powders with different milling conditions

\begin{tabular}{|c|c|c|c|}
\hline Milling conditions & $\boldsymbol{D}(\mathbf{0 . 1})(\mu \mathrm{m})$ & $\boldsymbol{D}(\mathbf{0 . 5})(\mu \mathrm{m})$ & $\boldsymbol{D}(\mathbf{0 . 9})(\mu \mathrm{m})$ \\
\hline $800 \mathrm{rpm}+20 \mathrm{~min}$ & 3.0 & 16.7 & 117.6 \\
\hline $800 \mathrm{rpm}+30 \mathrm{~min}$ & 2.2 & 8.8 & 77.2 \\
\hline $800 \mathrm{rpm}+45 \mathrm{~min}$ & 1.7 & 4.6 & 89.1 \\
\hline $800 \mathrm{rpm}+60 \mathrm{~min}$ & 1.9 & 6.3 & 96.2 \\
\hline
\end{tabular}

\section{CONCLUSIONS}

In this article, the role of different high energy ball milling conditions of molybdenum powder was investigated; namely BPR, milling atmosphere, PCA, rotational speed and milling time. The BPR was selected with respect 
to the greater variability of milling parameters in particle size reduction, and therefore the BPR (100:6) was chosen. There was no difference between milling in air or in nitrogen atmosphere for selected initial molybdenum powder, because of its no reactivity with air during milling that was confirmed in previous experiments. The milling with PCA (PEG) had a negative influence on particle size reduction. As the optimal milling speed was determined $800 \mathrm{rpm}$ with the milling time of $45 \mathrm{~min}$. Up to this milling time, the powder particles mainly tend to fracture. And after this point (milling for $60 \mathrm{~min}$ ), the powder particles started to grow and cold-weld in higher volume ( 10 vol\%). The volume of finer powder particles decreased for 15 vol\% in comparison to the volume of finer particles of milled powder at $45 \mathrm{~min}$. Powder milled at $45 \mathrm{~min}$ had two main particle size fractions with average size of $2 \mu \mathrm{m}$ and of $120 \mu \mathrm{m}$. While the finest particles were in size of $1.1 \mu \mathrm{m}$, the biggest particles were in size of $400 \mu \mathrm{m}$. For next experiments, the bigger particles than $36 \mu \mathrm{m}$ will be removed with the sieve.

\section{ACKNOWLEDGEMENTS}

This research was financially supported by CEITEC BUT, Brno University of Technology, under the grant CEITEC VUT-J-19-5933 and by COST CA18112 "Mechanochemistry for Sustainable Industry". We also acknowledge CEITEC Nano Research Infrastructure (MEYS CR, 2016-2019) for providing us with access to the SEM devices.

\section{REFERENCES}

[1] PRASAD, N. Eswara and WANHILL, R. J. H. Aerospace Materials and Material Technologies. 1. Singapore: Springer Singapore, 2017.

[2] DEAN, J.A. Lange's Handbook of Chemistry. McGraw-Hill Professional. 1998. 